\title{
Annealing effects on the structural and optical properties of $\mathrm{ZnO}$ nanoparticles with PVA and CA as chelating agents
}

\author{
A. N. MALLIKA*, A. Ramachandra REDDY, K. Venugopal REDDY \\ Department of Physics, Materials Science Laboratory, National Institute of Technology, \\ Warangal-506004, Telangana, India
}

Received: November 14, 2014; Revised: December 30, 2014; Accepted: January 24, 2015

(C) The Author(s) 2015. This article is published with open access at Springerlink.com

\begin{abstract}
The effects of annealing temperatures and chelating agents on the structural and optical properties of $\mathrm{ZnO}$ nanoparticles were investigated. The average particle size of $\mathrm{ZnO}$ nanoparticles increased with increase of annealing temperatures. The decrease of the full width at half maximum (FWHM) with increasing annealing temperatures inferred increase of particle/grain growth. The grain sizes were also observed to be increased with increase of annealing temperatures. From the absorption spectra of the samples, the absorption was red-shifted and the energy band gap was blue-shifted with increase of annealing temperatures. A sharp UV emission peak was observed and the intensity of this peak increased with annealing temperatures corresponding to the high crystallinity in the samples. At high annealing temperature of $700{ }^{\circ} \mathrm{C}, \mathrm{ZnO}$ exhibited a less intense deep level emission. This negligible deep level emission was attributed to the oxygen vacancies created at higher annealing temperatures.
\end{abstract}

Keywords: $\mathrm{ZnO}$ nanostructures; citric acid (CA); polyvinyl alcohol (PVA); chelating agents; scanning electron microscopy (SEM); optical properties

\section{Introduction}

Zinc oxide $(\mathrm{ZnO})$ is a wide-band-gap, wurtzite-type semiconductor with an energy gap of $3.37 \mathrm{eV}$ at room temperature. The large exciton binding energy and the wide band gap make it an excellent semiconductor material for applications considered for other wide-band-gap materials such as $\mathrm{GaN}$ and $\mathrm{SiC}$. Nanomaterials and nanostructures have shown their great potential in basic scientific research and technology applications due to their size effect and their promising applications in nano scaled devices [1]. As a versatile semiconductor, $\mathrm{ZnO}$ is a potential

\footnotetext{
* Corresponding author.

E-mail: mallika.nitw@gmail.com
}

functional material exhibiting many technological applications in photonic crystals, photo detectors, varistors, solar cells, transparent conductive films, and bulk acoustic wave devices and so on $[2,3]$. Furthermore, its properties can be tailored by synthesizing particles of specific size, especially in nano size. The $\mathrm{ZnO}$ nanocrystals always exhibit novel unique properties due to quantum confinement effects compared with the bulk $\mathrm{ZnO}$ [4]. Nevertheless, the properties of the $\mathrm{ZnO}$ nanocrystals depend closely on their particle size, morphology, surface area, and activity [5]. Further, to monitor the material properties in a controllable fashion, suitable temperatures and annealing ambient environment have to be chosen [6]. Numerous studies have reported that an optimum annealing treatment not only improves the crystallinity 
of $\mathrm{ZnO}$, but also changes the $\mathrm{Zn} / \mathrm{O}$ ratio and intrinsic defects [7]. Singh et al. [8] have reported the thermal annealing effects on the structural and optical properties of $\mathrm{ZnO}$ in terms of coarsening mechanism. With modified sol-gel combustion method, Zak et al. [9] have studied the structural and optical properties. At $500{ }^{\circ} \mathrm{C}$ annealing temperature, Yang et al. [10] have observed good emission properties with fewer defects. Kazemi et al. [11] have investigated the significant role of complexing agents on the structural and optical properties of $\mathrm{ZnO}$ nanoparticles with annealing treatment. However, the systematic study of the influence of annealing treatment on the structural and optical properties of $\mathrm{ZnO}$ nanoparticles with citric acid and polyvinyl alcohol as chelating agents has few reports.

In the present study, $\mathrm{ZnO}$ nanoparticles were prepared with citric acid (CA) and polyvinyl alcohol (PVA) as chelating agents. The samples were annealed at temperatures $400{ }^{\circ} \mathrm{C}, 500{ }^{\circ} \mathrm{C}, 600{ }^{\circ} \mathrm{C}$, and $700{ }^{\circ} \mathrm{C}$. The structural properties of the prepared samples were investigated by X-ray diffraction (XRD) and scanning electron microscopy (SEM). The optical properties were studied with Fourier transform infrared spectroscopy (FTIR), absorption spectroscopy, and photoluminescence (PL) emission spectra. Based on the results, the effect of annealing treatment with chelating agents on the structural and optical properties was discussed.

\section{Experimental}

For preparing $\mathrm{ZnO}$ nanoparticles, $\mathrm{Zn}\left(\mathrm{NO}_{3}\right)_{2} \cdot 6 \mathrm{H}_{2} \mathrm{O}$, $\mathrm{C}_{6} \mathrm{H}_{8} \mathrm{O}_{7}$, and $\left[-\mathrm{CH}_{2} \mathrm{CHOH}-\right]_{n}$ were taken as the starting chemicals. Zinc nitrate to chelating agent ratio was maintained as 1:3 throughout the experiment. In order to get $2 \mathrm{~g}$ of the final product, $0.8 \mathrm{M}$ zinc nitrate was first dissolved in $30 \mathrm{~mL}$ of deionised water. Then, $6 \mathrm{~g}$ of polyvinyl alcohol (PVA) was dissolved slowly in $60 \mathrm{~mL}$ of deionised water, and stirred vigorously till a homogenous milk white solution was obtained. Then, zinc nitrate solution was added dropwise to chelating (PVA) solution. This milk white solution was vigorously stirred on hot plate at $70{ }^{\circ} \mathrm{C}$ till the gel formation. The gel was kept in an oven to get dried powders at $100{ }^{\circ} \mathrm{C}$ for $6 \mathrm{~h}$. Finally, the as-prepared powders were annealed in a programmable muffle furnace with annealing rate $2{ }^{\circ} \mathrm{C} / \mathrm{min}$ to different annealing temperatures $400{ }^{\circ} \mathrm{C}, 500{ }^{\circ} \mathrm{C}, 600{ }^{\circ} \mathrm{C}$, and
$700{ }^{\circ} \mathrm{C}$ and holding time $1 \mathrm{~h}$. The same procedure was followed to prepare $\mathrm{ZnO}$ nanoparticles with citric acid (CA) as chelating agent. The samples were coded as per the annealing temperatures for simple understanding. For temperatures $400{ }^{\circ} \mathrm{C}, 500{ }^{\circ} \mathrm{C}, 600{ }^{\circ} \mathrm{C}$, and $700{ }^{\circ} \mathrm{C}$, the samples were coded as CA400, CA500, CA600, and CA700 with CA as chelating agent, respectively. In the same manner, PVA samples were also coded as PVA400, PVA500, PVA600, and PVA700 for temperatures $400{ }^{\circ} \mathrm{C}, 500{ }^{\circ} \mathrm{C}, 600{ }^{\circ} \mathrm{C}$, and $700{ }^{\circ} \mathrm{C}$, respectively.

The phase identification and crystallite sizes of the samples were determined using XRD patterns recorded on INEL XRG 3000 powder diffractometer equipped with Co $\mathrm{K} \alpha$ radiation $(\lambda=1.7889 \AA)$ in terms of $2 \theta$ ranging from $20^{\circ}$ to $120^{\circ}$. The morphology of the samples was studied with SEM model VEGA3TESCAN along with energy dispersive spectrometer (EDS). Formation of $\mathrm{ZnO}$ was confirmed from FTIR spectrum (Model: Perkin Elmer Spectrum-100) recorded in the wavenumber region $4000-400 \mathrm{~cm}^{-1}$. Optical absorption of the samples was recorded using UV-visible (UV-Vis) spectrophotometer (Model: Varian, Cary 5000 ) in the wavelength region $250-600 \mathrm{~nm}$. The PL measurements were performed on Jobin yuon spectrofluorometer (Model: Fluorolog-Fl3-11) equipped with a xenon lamp of $450 \mathrm{~W}$.

\section{Results and discussion}

\section{1 X-ray diffraction}

The XRD patterns of $\mathrm{ZnO}$ nanoparticles prepared with $\mathrm{CA}$ and PVA as chelating agents at annealing treatments $400{ }^{\circ} \mathrm{C}, 500{ }^{\circ} \mathrm{C}, 600{ }^{\circ} \mathrm{C}$, and $700{ }^{\circ} \mathrm{C}$ are given in Fig. 1. The reflection peaks at $2 \theta=37.123^{\circ}$, $40.246^{\circ}, 42.284^{\circ}, 55.850^{\circ}, 67.029^{\circ}$, and $74.369^{\circ}$ correspond to (100), (002), (101), (102), (110), and (103) reflection planes of $\mathrm{ZnO}$ hexagonal wurtzite structure, respectively. The XRD spectra reveal the influence of annealing treatments on the structural properties. The intensity of the peaks gets sharpened and increased with increasing annealing temperatures for both CA and PVA samples. Primarily, the increase in the peak intensities is attributed to increase of the crystallinity and crystallite size. In general, for $\mathrm{ZnO}$ there are many dangling bonds related to the zinc and oxygen defects at the grain boundaries. As a result, these defects are favourable for the merging process to form larger $\mathrm{ZnO}$ grain when increasing the annealing 
(a)

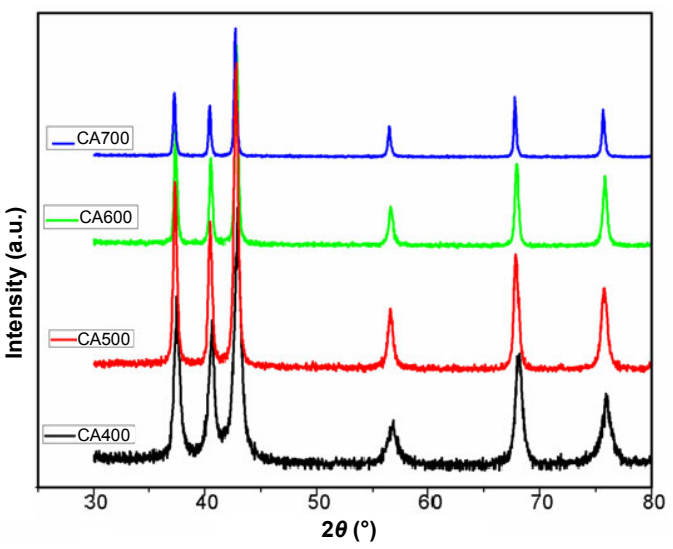

(b)

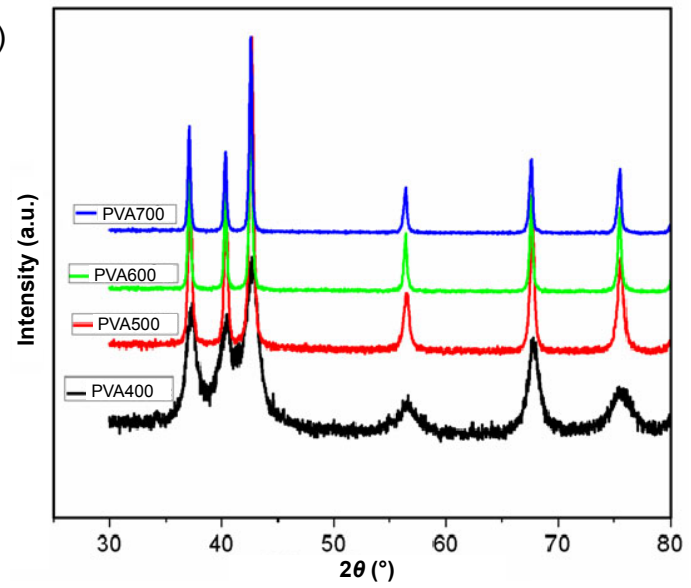

(c)

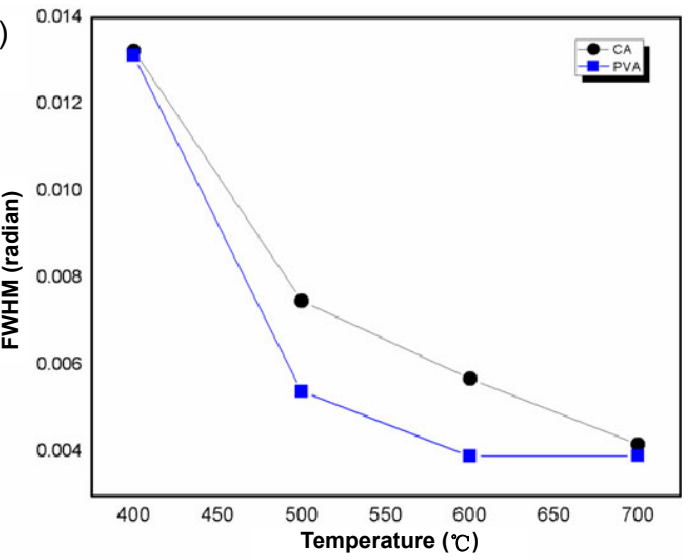

Fig. 1 (a) and (b) XRD patterns of $\mathrm{ZnO}$ nanoparticles annealed at temperatures $400{ }^{\circ} \mathrm{C}, 500{ }^{\circ} \mathrm{C}, 600{ }^{\circ} \mathrm{C}$, and $700{ }^{\circ} \mathrm{C}$ with (a) CA and (b) PVA as chelating agents. (c) Variation of the FWHM with annealing treatments.

temperatures [12]. The average crystallite sizes of all the samples were calculated using Debye-Scherrer formula [13] and are tabulated in Table 1. The average crystallite sizes increase with increasing annealing temperatures, from 13 (at $400{ }^{\circ} \mathrm{C}$ ) to $41 \mathrm{~nm}$ (at $700{ }^{\circ} \mathrm{C}$ ) for CA samples. For PVA samples, it has increased from 7 (at $400{ }^{\circ} \mathrm{C}$ ) to $36 \mathrm{~nm}\left(\right.$ at $700{ }^{\circ} \mathrm{C}$ ). In addition,
Table 1 Crystallite size $D$ estimated from the FWHM values at different annealing temperatures

Temperature CA as chelating agent PVA as chelating agent

\begin{tabular}{|c|c|c|c|c|}
\hline$\left({ }^{\circ} \mathrm{C}\right)$ & FWHM (radian) & $D(\mathrm{~nm})$ & FWHM (radian) & $D(\mathrm{~nm})$ \\
\hline 400 & 0.01324 & 13 & 0.023230 & 7 \\
\hline 500 & 0.00749 & 23 & 0.007400 & 23 \\
\hline 600 & 0.00570 & 30 & 0.004680 & 35 \\
\hline 700 & 0.00418 & 41 & 0.004704 & 36 \\
\hline
\end{tabular}

the full width at half maximum (FWHM) values decrease with increase of annealing temperatures as shown in Fig. 1(c). The changes in FWHM can be correlated to the grain sizes [14]; the smaller FWHM indicates a larger grain size and a better crystal quality, which may be due to the recrystallization process with sufficient thermal energy supply.

\section{2 Scanning electron microscopy}

Microstructural characterization of synthesized samples was studied by SEM analysis. For morphological studies, gold coating was provided on the powder sample placed over a carbon tape. Figures 2(a) and 2(b) depict the SEM images of $\mathrm{ZnO}$ nanostructure with CA and PVA as chelating agents annealed at various temperatures, respectively. The grain size of the samples was determined by counting sufficiently large number of grains to ensure the accuracy. The average grain size of PVA and CA samples is in the range of $50-100 \mathrm{~nm}$ as indicated in Figs. 2(a) and 2(b). With increasing annealing temperatures, the grain growth is observed in both samples. The compositions of $\mathrm{ZnO}$ nanoparticles with different chelating agents were determined through EDS, which is shown in Fig. 2(c).

\section{3 Fourier transform infrared spectroscopy}

Chemical and structural changes that take place during the heat treatment can be monitored by a spectroscopic analysis. Figure 3 depicts the FTIR spectra of the annealed samples CA400, CA500, CA600, CA700, PVA400, PVA500, PVA600, and PVA700. Two strong frequency bands are observed in all the samples at 556- $445 \mathrm{~cm}^{-1}$ corresponding to characteristics of $\mathrm{ZnO}$ wurtzite structure [15]. The peaks observed at 1600 and $1384 \mathrm{~cm}^{-1}$ are assigned to the asymmetrical and symmetrical stretching of zinc carboxylate, respectively [16]. Further, for PVA samples these peaks persist till higher annealing temperatures, whereas for CA they are eliminated completely. This may be analysed as following: as the size of the nanoparticles 
(a)

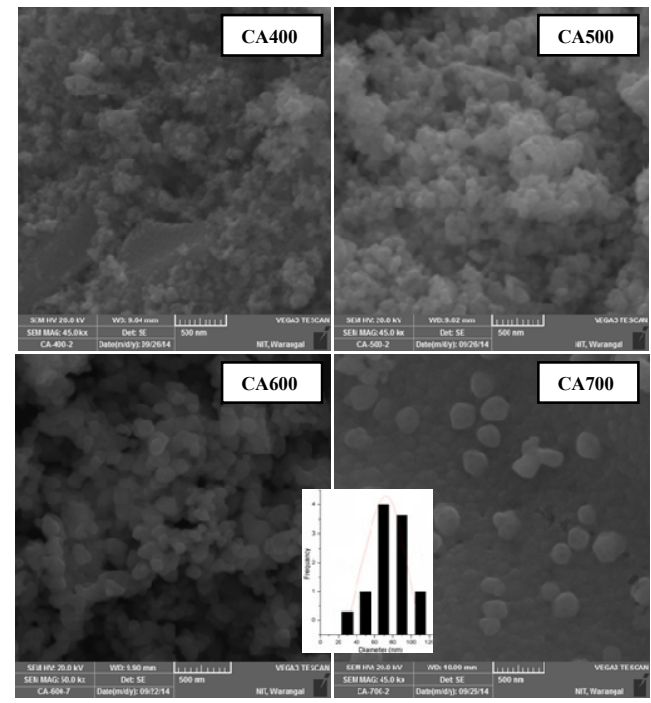

(b)

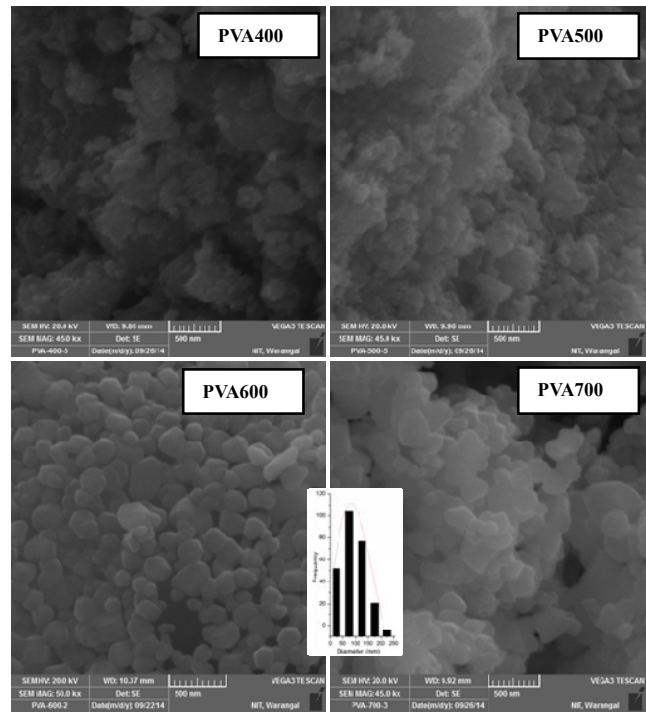

(c)
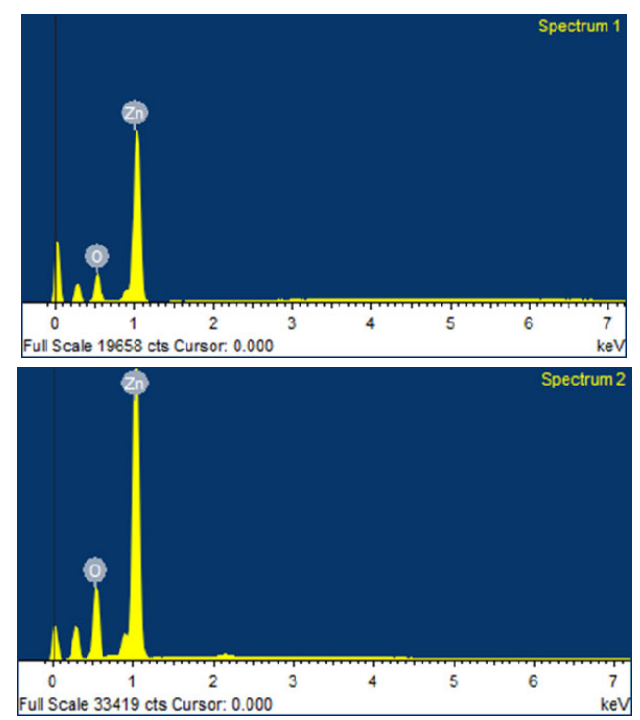

Fig. 2 (a) and (b) Morphology of $\mathrm{ZnO}$ nanoparticles annealed at temperatures $400{ }^{\circ} \mathrm{C}, 500{ }^{\circ} \mathrm{C}, 600{ }^{\circ} \mathrm{C}$, and $700{ }^{\circ} \mathrm{C}$ with (a) CA and (b) PVA as chelating agents. (c) Compositions of $\mathrm{ZnO}$ nanoparticles with CA (upper) and PVA (lower) as chelating agents. (a)

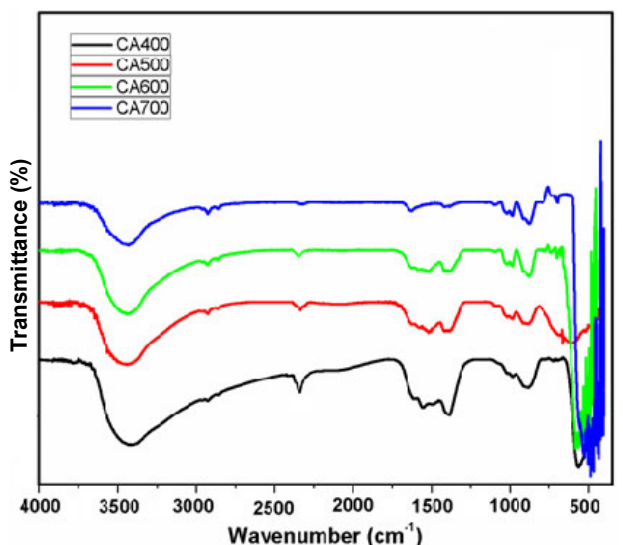

(b)

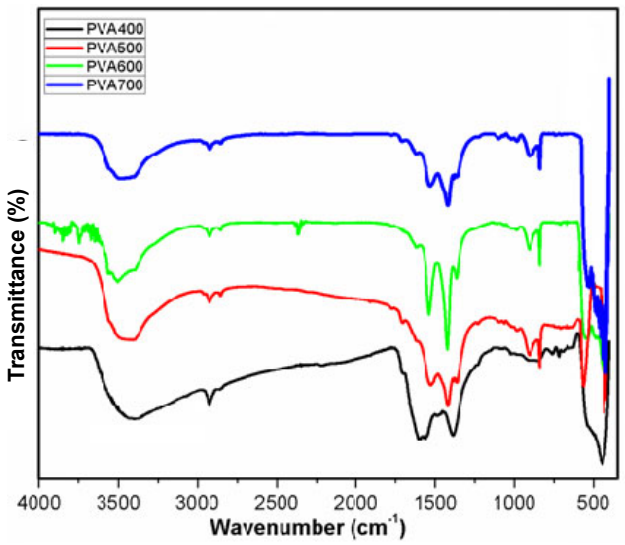

Fig. 3 FTIR spectra of $\mathrm{ZnO}$ with (a) CA and (b) PVA as chelating agents.

increases with increase of annealing temperatures, the content of the carboxylate (COO-) and hydroxyl $(-\mathrm{OH})$ groups in the samples decreases. The carboxylate probably comes from reactive carbon containing plasma species during synthesis and the hydroxyl results from the hygroscopic nature of $\mathrm{ZnO}$. Annealing at $700{ }^{\circ} \mathrm{C}$ significantly reduces these carboxylate and hydroxyl impurities in all samples for CA, whereas for PVA they persist till higher temperatures as shown in Fig. 3. Besides this, a band around $1384 \mathrm{~cm}^{-1}$ is attributed to the anti-symmetric $\mathrm{NO}_{3}^{-1}$ stretching vibration [17]. In addition to these bands, there is a low-intensity frequency band around $2900 \mathrm{~cm}^{-1}$ corresponding to the stretching vibration of $\mathrm{CH}_{2}$ implying the presence of PVA and CA [18]. It has been confirmed from these bands that small amount of the chelating agent present on the surface of the sample which stabilizes the $\mathrm{ZnO}$ nanostructures [19]. The intensity of these bands reduces as a function of annealing temperature indicating the formation of pure wurtzite structure. Together, this suggests that these FTIR-identified impurities mainly exist near $\mathrm{ZnO}$ surface. 


\section{4 UV-Vis absorption}

The UV-Vis absorption spectra of the $\mathrm{ZnO}$ nanoparticles prepared with CA and PVA as chelating agents annealed at temperatures $400{ }^{\circ} \mathrm{C}, 500{ }^{\circ} \mathrm{C}$, $600{ }^{\circ} \mathrm{C}$, and $700{ }^{\circ} \mathrm{C}$ are shown in Fig. 4(a). The relevant increase in the absorption at wavelengths less than $400 \mathrm{~nm}$ can be assigned to the intrinsic band-gap absorption of $\mathrm{ZnO}$ due to the electron transitions from the valence band to the conduction band $\left(\mathrm{O}_{2 \mathrm{p}}-\mathrm{Zn}_{3 \mathrm{~d}}\right)$ [20]. Interestingly, an obvious red shift in the absorption edge is observed for both the products. Zak et al. [9] have observed the same phenomenon; this may be assigned to changes in their morphologies, particle size, and surface microstructures. A practical method is to equate $E_{\mathrm{g}}$ with the wavelength at which the absorption is $50 \%$ of the excitonic peak (shoulder), called $\lambda_{1 / 2}$ [21]. This is schematically shown in Fig. 4(b). The energy band gap $E_{\mathrm{g}}\left(\lambda_{1 / 2}\right)$ of $\mathrm{ZnO}$ nanoparticles calculated are shown in Table 2. The increase in the $\mathrm{ZnO}$ band gap energy is in good agreement with the corresponding red shift observed in the absorption edge mentioned above. Further, from effective mass approximation, the energy corresponding to the exciton absorption peak has been

(a)

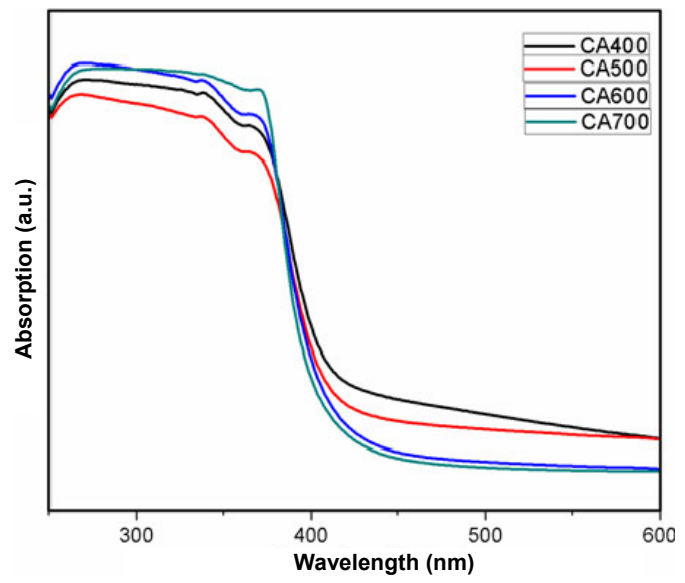

(b)

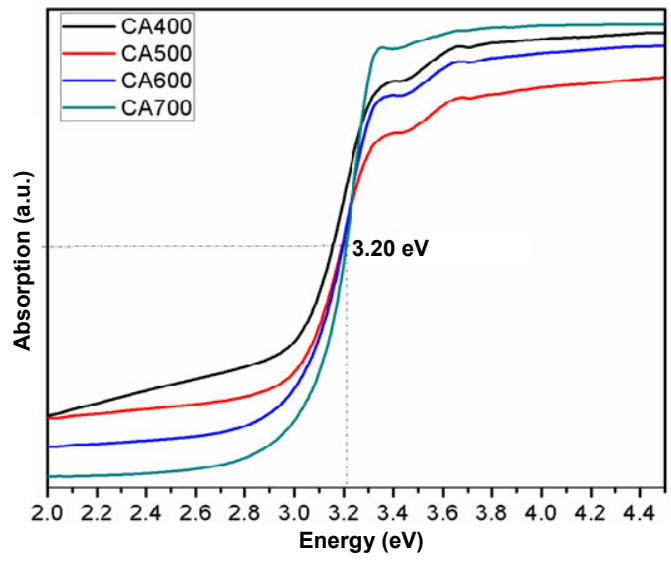

converted in terms of particle size [22]:

$E=E_{\mathrm{g}}+h^{2} \pi^{2}\left(\frac{1}{m_{\mathrm{e}}}+\frac{1}{m_{\mathrm{h}}}\right)-\left(\frac{1.8 e^{2}}{4 \pi \varepsilon^{\prime} \varepsilon_{0} R}\right)+$ smaller term

where $E$ is the band gap of the synthesised particle; $E_{\mathrm{g}}$ is the bulk energy of $\mathrm{ZnO} ; R$ is the radius of the particle; $m_{\mathrm{e}}$ is the effective mass of the electron $\left(0.28 m_{0}\right) ; \quad m_{\mathrm{h}}$ is the effective mass of the hole $\left(0.49 m_{0}\right) ; \varepsilon^{\prime}$ is the dielectric constant of the material $(9.1) ; \varepsilon_{0}$ is the permittivity of the free space; and $h$ is the Planck's constant. The obtained values of the particle radius using the mass approximation are observed to be increased with increase of the annealing temperatures and are tabulated in Table 2.

Table 2 Particle size $R$ value using effective mass approximation and their corresponding energy band gap value with varying annealing temperatures

\begin{tabular}{|c|c|c|c|c|}
\hline \multirow[b]{2}{*}{$\begin{array}{c}\text { Temperature } \\
\left({ }^{\circ} \mathrm{C}\right)\end{array}$} & \multicolumn{2}{|c|}{ Energy band gap (eV) } & \multicolumn{2}{|c|}{ Particle size $R(\mathrm{~nm})$} \\
\hline & $\begin{array}{c}\text { CA as } \\
\text { chelating } \\
\text { agent }\end{array}$ & $\begin{array}{c}\text { PVA as } \\
\text { chelating } \\
\text { agent }\end{array}$ & $\begin{array}{c}\text { CA as } \\
\text { chelating } \\
\text { agent }\end{array}$ & $\begin{array}{c}\text { PVA as } \\
\text { chelating } \\
\text { agent }\end{array}$ \\
\hline 400 & 3.14 & 2.99 & 2.37 & 2.44 \\
\hline 500 & 3.17 & 3.16 & 2.79 & 2.62 \\
\hline 600 & 3.19 & 3.19 & 2.92 & 3.24 \\
\hline 700 & 3.20 & 3.20 & 2.85 & 2.79 \\
\hline
\end{tabular}
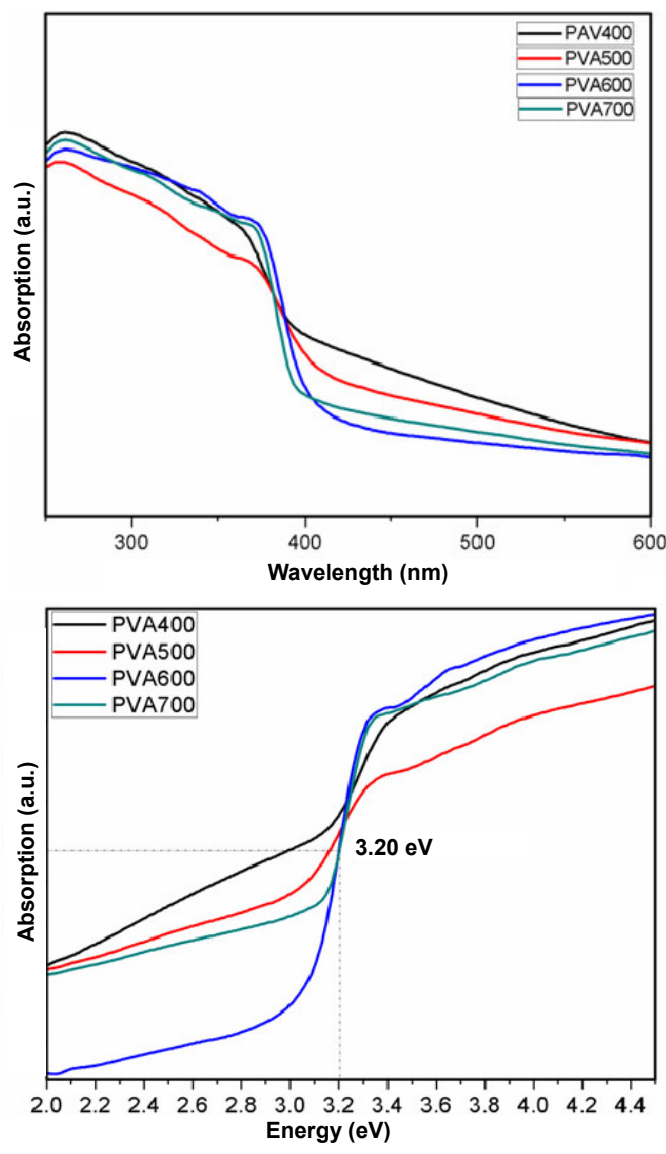

Fig. 4 (a) Absorption of $\mathrm{ZnO}$ nanoparticles annealed at different temperatures; (b) absorption profile of $\mathrm{ZnO}$ with annealing treatments 


\section{5 Photoluminescence}

The PL spectroscopy is an effective method to investigate the presence of defects in semiconductors [23]. Figure 5 shows the PL spectra of $\mathrm{ZnO}$ nanoparticles annealed at different temperatures with CA and PVA as chelating agents. It is observed from the Fig. 5 that, $\mathrm{ZnO}$ nanoparticles exhibit a strong excitonic related UV emission positioned at $395 \mathrm{~nm}$ for all the annealing temperatures. The intensity of this UV emission peak increases monotonously with increase of annealing temperatures. As the increase in the UV emission is associated with the grain and crystal orientation [24], this can be further analysed as, with increase of the annealing temperatures, there is a reduction in the grain boundaries and the number of particles on the surface of $\mathrm{ZnO}$ nanoparticles. Consequently, the number of non-radiative transitions and deep level defects are supressed together, and thereby UV emission intensity has increased [6]. This can be further attributed to the reduciton of the carboxylates and hydroxyl impurities with increase of annelaing temperatures as observed in FTIR analysis. As the carboxylates and hydroxyl impurites serve as the non-radiative recombination centers during the relaxation process, the non-radiative transitions are

(a)

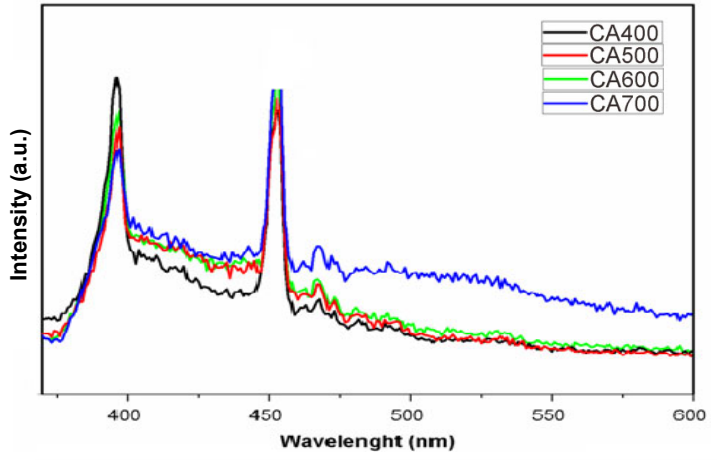

(b)

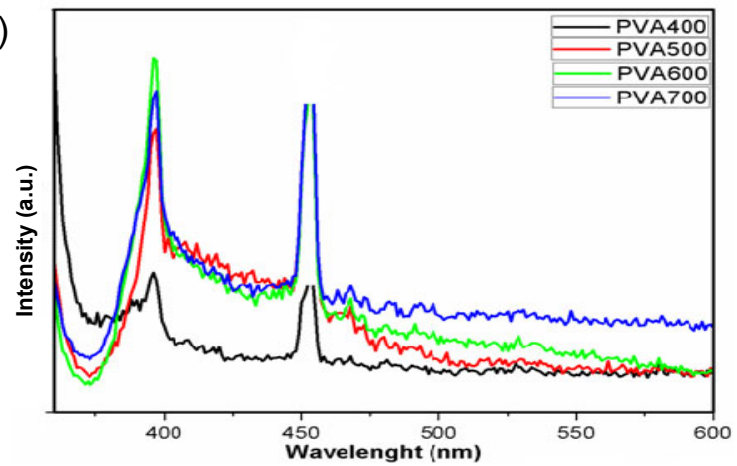

Fig. 5 PL spectra of $\mathrm{ZnO}$ annealed at temperatures $400{ }^{\circ} \mathrm{C}, 500{ }^{\circ} \mathrm{C}, 600{ }^{\circ} \mathrm{C}$, and $700{ }^{\circ} \mathrm{C}$ with (a) CA and (b) PVA as chelating agents. supressed. This behaviour indicates the improvement in the crystalline nature of the samples [25]. With increasing annelaing temperatures, some defect related emission is observed at higher temperature $\left(700{ }^{\circ} \mathrm{C}\right) . \mathrm{In}$ general, for the high-temperature annealing in air, the formation of $\mathrm{Zn}_{\mathrm{i}}$ (zinc interstitials) and $\mathrm{V}_{\mathrm{O}}$ (oxygen vacancies) is favourable [26]. Therefore, in the present study, the negligible emission occurring at high temperature $700{ }^{\circ} \mathrm{C}$ may be assigned to $\mathrm{Zn}_{\mathrm{i}}$ and $\mathrm{V}_{\mathrm{O}}$ defect states.

\section{Conclusions}

The wurtzite structure of $\mathrm{ZnO}$ was confirmed from the diffraction patterns of the samples. The average particle sizes estimated from the XRD results were observed to be increased with increasing annealing temperatures for both CA and PVA samples. The reduction in the FWHM with increasing temperatures has confirmed the improved crystallinity of the samples. The grain growth was further confirmed from SEM. From FTIR studies, with increase of annealing temperatures, the presence of carboxylate and hydroxyl impurities was reduced as the particle size increased. Further, this was reflected in the emission spectra, as the non-radiative recombination transitions were suppressed with increase of the particle sizes with increase of annealing temperatures. The optical band gap of the samples was blue-shifted with temperatures indicating particle size growth, and the particle sizes estimated using effective mass approximation corroborated the same. The increase in the intensity of the UV emission peaks with increase of annealing temperatures corroborated the XRD results. Along with a strong UV emission, some defect related emissions exhibited at higher temperature $700{ }^{\circ} \mathrm{C}$. This defect related emission was assigned to the oxygen vacancies created at higher annealing temperatures.

\section{Acknowledgements}

The authors are thankful to the dean of School of Physics, University of Hyderabad, for providing XRD facility. The authors also would like to thank the Sophisticated Analytical Instrument Facility (SAIF) STIC India, Cochin, for the characterization of absorption spectra of the samples.

Open Access: This article is distributed under the 
terms of the Creative Commons Attribution License which permits any use, distribution, and reproduction in any medium, provided the original author(s) and the source are credited.

\section{References}

[1] Uthirakumar P, Hong C-H. Effect of annealing temperature and $\mathrm{pH}$ on morphology and optical property of highly dispersible $\mathrm{ZnO}$ nanoparticles. Mater Charact 2009, 60: 1305-1310.

[2] Lee JB, Kim HJ, Kim SG, et al. Deposition of $\mathrm{ZnO}$ thin films by magnetron sputtering for a film bulk acoustic resonator. Thin Solid Films 2003, 435: 179-185.

[3] Minami T, Ida S, Miyata T, et al. Transparent conducting $\mathrm{ZnO}$ thin films deposited by vacuum arc plasma evaporation. Thin Solid Films 2003, 445: 268-273.

[4] Seelig EW, Tang B, Yamilov A, et al. Self-assembled 3D photonic crystals from $\mathrm{ZnO}$ colloidal spheres. Mater Chem Phys 2003, 80: 257-263.

[5] $\mathrm{Hu} \mathrm{Y}$, Chen H-J. Preparation and characterization of nanocrystalline $\mathrm{ZnO}$ particles from a hydrothermal process. J Nanopart Res 2008, 10: 401-407.

[6] Dutta S, Chattopadhyay S, Sarkar A, et al. Role of defects in tailoring structural, electrical and optical properties of ZnO. Prog Mater Sci 2009, 54: 89-136

[7] Fang ZB, Yan ZJ, Tan YS, et al. Influence of post-annealing treatment on the structure properties of ZnO films. Appl Surf Sci 2005, 241: 303-308.

[8] Singh RG, Singh F, Kumar V, et al. Growth kinetics of ZnO nanocrystallites: Structural, optical and photoluminescence properties tuned by thermal annealing. Curr Appl Phys 2011, 11: 624-630.

[9] Zak AK, Abrishami ME, Abd MWH, et al. Effects of annealing temperature on some structural and optical properties of $\mathrm{ZnO}$ nanoparticles prepared by a modified sol-gel combustion method. Ceram Int 2011, 37: 393-398.

[10] Yang J, Liu X, Wang Y, et al. Effect of annealing temperature on the structure and optical properties of $\mathrm{ZnO}$ nanoparticles. J Alloys Compd 2009, 477: 632-635.

[11] Kazemi A, Abadyan M, Ketabi A. Controlled structural and optical properties of $\mathrm{ZnO}$ nano-particles. Phys Scr 2010, 82: 035801

[12] Kuo S-Y, Chen W-C, Cheng C-P. Investigation of annealing-treatment on the optical and electrical properties of sol-gel-derived zinc oxide thin films. Superlattice Microst 2006, 39: 162-170.

[13] Mallika AN, Reddy AR, Babu KS, et al. Synthesis and optical characterization of aluminum doped $\mathrm{ZnO}$ nanoparticles. Ceram Int 2014, 40: 12171-12177.
[14] Ravichandran C, Srinivasan G, Lennon C, et al. Influence of post-deposition annealing on the structural, optical and electrical properties of $\mathrm{Li}$ and $\mathrm{Mg}$ co-doped $\mathrm{ZnO}$ thin films deposited by sol-gel technique. Superlattice Microst 2011, 49: $527-536$.

[15] Mallika AN, Reddy AR, Babu KS, et al. Structural and photoluminescence properties of $\mathrm{Mg}$ substituted $\mathrm{ZnO}$ nanoparticles. Opt Mater 2014, 36: 879-884.

[16] Xiong G, Pal U, Serrano JG, et al. Photoluminescence and FTIR study of $\mathrm{ZnO}$ nanoparticles: The impurity and defect perspective. Phys Status Solidi c 2006, 3: 3577-3581.

[17] Sujatha Ch., Reddy KV, Babu KS, et al. Effects of heat treatment conditions on the structural and magnetic properties of $\mathrm{MgCuZn}$ nano ferrite. Ceram Int 2012, 38: 5813-5820.

[18] Kim SJ, Park SJ, Kim SI. Swelling behavior of interpenetrating polymer network hydro gels composed of poly(vinyl alcohol) and chitosan. Reactive \& Functional Polymers 2003, 55: 53-59.

[19] Razavi RS, Loghman-Estarki MR, Farhadi-Khouzani M, et al. Large scale synthesis of zinc oxide nano- and submicro-structures by Pechinis method: Effect of ethylene glycol/citric acid mole ratio on structural and optical properties. Curr Nanosci 2011, 7: 807-812.

[20] Yu H, Yu J, Cheng B, et al. Effects of hydrothermal post-treatment on microstructures and morphology of titanate nanoribbons. J Solid State Chem 2006, 179: 349-354.

[21] Sharma A, Singh BP, Dhar S, et al. Effect of surface groups on the luminescence property of $\mathrm{ZnO}$ nanoparticles synthesized by sol-gel route. Surf Sci 2012, 606: L13-L17.

[22] Singh AK, Viswanath V, Janu VC. Synthesis, effect of capping agents, structural, optical and photoluminescence properties of $\mathrm{ZnO}$ nanoparticles. $J$ Lumin 2009, 129: 874-878.

[23] Srinet G, Varshney P, Kumar R, et al. Structural, optical and magnetic properties of $\mathrm{Zn}_{1-x} \mathrm{Co}_{x} \mathrm{O}$ prepared by the sol-gel route. Ceram Int 2013, 39: 6077-6085.

[24] Hsieh PT, Chen YC, Kao KS, et al. The ultraviolet emission mechanism of $\mathrm{ZnO}$ thin film fabricated by sol-gel technology. J Eur Ceram Soc 2007, 27: 3815-3818.

[25] Gondal MA, Drmosh QA, Yamani ZH, et al. Synthesis of $\mathrm{ZnO}_{2}$ nanoparticles by laser ablation in liquid and their annealing transformation into $\mathrm{ZnO}$ nanoparticles. Appl Surf Sci 2009, 256: 298-304.

[26] Xu J, Shi S, Zhang X, et al. Structural and optical properties of $(\mathrm{Al}, \mathrm{K})$-co-doped $\mathrm{ZnO}$ thin films deposited by a sol-gel technique. Mat Sci Semicon Proc 2013, 16: $732-737$. 